\title{
Role of Microgel Formation in Scavenging of Chromophoric Dissolved Organic Matter and Heavy Metals in a River-Sea System
}

Ruei-Feng Shiu ${ }^{1}$, Chon-Lin Lee ${ }^{1,2,3,4 *}$

${ }^{1}$ Department of Marine Environment and Engineering, National Sun Yat-sen University, Kaohsiung, Taiwan

${ }^{2}$ Department of Public Health, College of Health Science, Kaohsiung Medical University, Kaohsiung, Taiwan

${ }^{3}$ Asia-Pacific Ocean Research Center, National Sun Yat-sen University, Kaohsiung, Taiwan

${ }^{4}$ Research Center for Environmental Medicine, Kaohsiung Medical University, Kaohsiung, Taiwan

* Correspondence author. Department of Marine Environment and Engineering, National Sun Yat-sen University, Kaohsiung, Taiwan. Tel: 886-7-5252000-5066; Fax: 886-7-5255066. Email: linnohc@fac.nsysu.edu.tw. 


\begin{abstract}
We use riverine and marine DOC polymers to examine their aggregation behavior, and to evaluate the roles of microgel formation in scavenging of chromophoric dissolved organic matter (CDOM) and heavy metals in a river-sea system. Our results indicate that riverine and marine microgels did not exhibit very much difference in size and self-assembly curve; however, the assembly effectiveness ([microgel]/DOC) of marine samples was much higher than riverine. Instead of concentration of DOC, other factors such as types and sources of DOC polymers may control the microgel abundance in aquatic environments. After filtering water samples (microgels removed), the $\mathrm{CDOM}$ and selected metals $(\mathrm{Cu}, \mathrm{Ni}, \mathrm{Mn})$ in the filtrate were quantified. $\mathrm{CDOM}$ and metals were concurrently removed to an extent via DOC polymer re-aggregation, which also suggested that the microgels had sequestering capability in CDOM and metals. This finding provides an alternative route for CDOM and heavy metals removal from the water column. As such the process of re-aggregation into microgels should then be considered besides traditional phase partitioning in the assessment of the ecological risk and fate of hazardous materials.
\end{abstract}

Keywords: Microgel, Aggregation, Chromophoric dissolved organic matter, Heavy metals, Scavenging.

\title{
1. Introduction
}

Aquatic dissolved organic carbon is one of the largest pools of reduced carbon on Earth and also one of the most complex organic mixtures in the environment system. Organic materials can be derived from various natural and anthropogenic sources including photosynthetic production, bacterial activity, terrestrial input, and industrial effluents. The impacts of these materials, including colloid or DOC biopolymers, on the ecosystem, could be vast, for example, in their participation in various biogeochemical reactions such as microbial loop, element exchange, light absorption and food webs $[1,2]$. Some studies also indicated that DOC alters the mobility of pollutants which in turn affects their bioavailability, and acts as a critical regulator for pollutant toxicity [3-5]. The capability of these materials comes from some functional groups present within the natural organic matter structure, such as polysaccharides, proteins, lipids, nucleic acids and various functional group types (carboxylate, sulfate, and phosphate) [6-8]. These functional groups have the potential to provide highly stable binding and adsorbing sites with metal ions and organic compounds [9-11]. It is therefore generally acknowledged that DOC can serve as natural organic ligands to sequester organic and inorganic materials and thus influence their availability to organisms $[4,12]$. 
Marine DOC polymers were first shown to form self-assembly aggregates as an ionic-bond-stabilized tangle network, with size ranging from molecules to an approximate size of 3-5 $\mu \mathrm{m}$ microgels [13]. This DOC-particulate organic carbon (POC) conversion is also believed to play a crucial role in marine snow, micro-aggregates and biofilms formation [14] and in the vertical transport of carbon, nutrients and elements [15-17]. Recent observations confirmed unambiguously that, besides in the ocean, these self-assembly aggregates of DOC polymers are also present in natural environments such as coastal, lake and river water $[13,18,19]$. The process of self-assembly aggregation into larger sinking particles is not well studied in the river-sea system, although it should be an important process in the fate and transport of organic matter. This process should also have significant implications on contaminant or surrounding material transport, which has not been well studied either [20-23]. In addition, the scavenging of particulate pollutants is well known in the estuarine region and is a significant process in quantifying land-derived natural and anthropogenic chemicals into shelf seas [24, 25]. It is believed that the microgel formation should have a contribution to the process through self-assembly and sinking particle processes [26, 27]. Besides, anthropogenic activities such as wastewater discharge are believed to alter DOC composition, chemical characteristic, concentration, and reactivity, especially in densely populated or industrial areas. Therefore, further study of re-aggregation of aquatic DOC in river-sea systems is needed to understand the role of microgel formation in scavenging surrounding materials via vertical transport.

In this study, we collected water samples from the Houjin River basin to the Taiwan Strait. This river flows through a metropolitan area and receives domestic and industrial discharges, with heavy metals and organic pollutants [28]. As the adsorptive and adhesive behaviors of aquatic organic materials by micro- and macrogels in an aquatic system are currently unclear [29], our principal aim was to examine the mechanism of aquatic microgel formation and to investigate the interaction of microgels with CDOM and metals in samples with different environmental parameters (river to sea). We tested the capacity of different types of DOC polymers forming microgels and their sequestering inorganic/organic materials in a river-sea system. The results will facilitate progress in the understanding of the behavior of different types of DOC polymers forming microgels and provide new insights into the interaction between aquatic surrounding materials and microgels.

\section{Material and Methods}

\subsection{Sampling and pre-treatment}

Three water samples were collected from the Houjin River to the Taiwan Strait in 
December 2013. The Houjin River originates from two upstream branches, passing through four major Kaohsiung industrial parks and Yuanjhonggang Creek water intake stations and extending all the way down to the Taiwan Strait. Water samples were collected in precleaned glass bottles at each sampling site. Polyethylene bottles holding water samples for metal analysis were pre-cleaned by $10 \% \mathrm{HNO}_{3}$ and rinsed with Milli-Q water. After collection, these samples were returned to the laboratory and kept in the dark until further processing.

The analysis of chemical parameters $\left(\mathrm{pH}\right.$, salinity, temperature, suspended solid, $\mathrm{Ca}^{2+}$ and $\mathrm{Mg}^{2+}$ ) was based on the standard methods of the National Institute of Environment Analysis (NIEA, Taiwan EPA). The DOC concentration (passed through a $0.22 \mu \mathrm{m}$ PVDF filter, Merck Millipore Ltd.) was measured as total carbon by catalytic high-temperature oxidation using a total organic carbon analyzer (OI Analytical, Aurora Model $1030 \mathrm{~W}$ ). An overview of all chemical characteristics of the water samples is provided in Table 1 . Salinity as an indicator of water types was ranged between $0.2 \mathrm{psu}$ for fresh water (upstream), followed by brackish water (downstream, $22.6 \mathrm{psu}$ ), and sea water (Taiwan Strait, $33.7 \mathrm{psu}$ ). A similar trend was observed for the concentration of $\mathrm{Ca}^{2+}$ and $\mathrm{Mg}^{2+}$. The upstream sample had the highest concentration of DOC and suspended solid (SS).

\subsection{Self-assembly of DOC polymer and microgel concentration measurement}

All DOC samples were passed through a $0.22 \mu \mathrm{m}$ filter which was pre-washed $(0.1 \mathrm{~N}$ $\mathrm{HCl}$ ) and rinsed with Milli-Q water (Millipore $18.2 \mathrm{M} \Omega \cdot \mathrm{cm}$ ). To inhibit microbial activity, $3 \mathrm{mM}$ sodium azide was added to water samples, which were then stored in the dark at $4{ }^{\circ} \mathrm{C}$. The aggregate size of DOC was monitored by MoFlo ${ }^{\mathrm{TM}}$ XDP Flow Cytometry (FC, Beckman Coulter, Indianapolis, IN). This instrument was set at the $488 \mathrm{~nm}$ laser and emission at $170 \mathrm{~mW}[13,30]$. The size calibration of the FC was evaluated using a standard suspension of polystyrene latex microspheres (Spherotech, Inc., Libertyville, IL). Each measurement was replicated ( $\geqq 5)$ in a $1 \mathrm{~mL}$ water sample at room temperature. The microgel concentration was determined by weight method. In brief, samples of the microgel were collected at $240 \mathrm{hrs}$ and filtered through a $0.22 \mu \mathrm{m}$ membrane. Then the membrane was washed with three portions of Milli-Q water $(150 \mathrm{~mL})$ to avoid salt interference, and was weighed after drying the membrane (Mettler-Toledo XS105DU analytical balance).

\subsection{Scanning electron microscopy (SEM)}

SEM images were used to confirm aquatic DOC polymer networks. Samples of microgel collected at $240 \mathrm{hrs}$ were taken and the assembled microgels retained on filters were observed using FEI Quanta 200 SEM (North America NanoPort, Portland, 
OR). The sample preparation was adopted from our previous study [31]. Microgel aggregation was filtered through a $0.22 \mu \mathrm{m}$ Millipore Isopore ${ }^{\mathrm{TM}}$ membrane (Fisher Scientific, Los Angeles, CA). The fixed microgels were dehydrated by soaking them in serially diluted ethanol $(35 \%, 50 \%, 70 \%, 95 \%$, and $100 \%$ ethanol) for 5 min and then coated in gold in preparation for viewing with SEM.

\subsection{Fluorescence enhancement measurement}

Chlortetracycline hydrochloride (CTC) was used as a bound $\mathrm{Ca}^{2+}$ indicator as in previous studies that reveal bound $\mathrm{Ca}^{2+}$ on polymers [32, 33]. All of the water samples were labeled with CTC $(100 \mu \mathrm{M})$. The fluorescence measurements were carried out with a Shimadzu RF-5000U spectrofluorophotometer $\left(\lambda_{\mathrm{ex}}=390 \mathrm{~nm}, \lambda_{\mathrm{em}}=\right.$ $530 \mathrm{~nm})$.

\subsection{Three-dimensional excitation-emission matrix fluorescence spectroscopy}

All the three-dimensional EEM spectra were obtained using a luminescence spectrometry (F-4500 FL Spectrophotometer, Hitachi, Japan), following protocols presented in a previous study [34]. EEM spectra are a collection of a series of emission spectra over a range of excitation wavelengths, which can be used to identify the fluorescent compounds present in complex mixtures. In this study, the scanning wavelength range was set: excitation wavelength (Ex) 220-500 nm (every $5 \mathrm{~nm}$ ), emission wavelength (Em) 260-700 nm (every $5 \mathrm{~nm}$ ), and the scanning speed was set at $2400 \mathrm{~nm} / \mathrm{min}$. The spectrum of Milli-Q water was recorded as the blank. The software Surfer 8 (Golden Software, Inc., Golden, $\mathrm{CO}$ ) was employed to process the EEM data.

\subsection{Dissolved metal measurement}

After water samples were PVDF filtered and UV-irradiated (releasing heavy metals from DOC-metal complexes) [35], the samples were concentrated based on the NIEA W308.22B method. Dissolved concentrations of selected metals $(\mathrm{Cu}, \mathrm{Ni}, \mathrm{Mn})$ were then determined by a Z-2000 series polarized Zeeman Atomic Absorption Spectrometer (Hitachi, Japan), equipped with an auto-sampler. Spike recoveries of the metals analyses were in the range of $94 \%$ to $104 \%$.

\subsection{Statistical analysis}

The data in this study were presented as means \pm standard deviation (SD). Statistically, significant differences were based on results of Student's t-test analysis with $p$ values of 0.05. Statistical analysis was assessed using Microsoft Office Excel and GraphPad Prism 4.0 (GraphPad Software, Inc., San Diego, CA). 


\section{Result and discussion}

\subsection{Self-assembly of riverine and marine DOC into microgel}

As shown in Fig. 1, the self-assembly of the riverine and marine DOC polymers was demonstrated as monitored by FC for over ten days. This indicates DOC polymers in $0.22 \mu \mathrm{m}$ filtered freshwater and seawater samples can spontaneously re-aggregate to form microgels. The microgel size and the self-assembly trend do not exhibit remarkable differences between the three water types at $240 \mathrm{hrs}(\mathrm{p}>0.05)$, and the final size of the microgels reached approximately 3-4 $\mu \mathrm{m}$ within $72 \mathrm{hrs}$. The equilibrium size of the microgels growing no bigger than $4-5 \mu \mathrm{m}$ is most likely because the average DOC polymer chain length is rather limited [36-38]. The equilibrium size of the microgels was also confirmed by SEM images of microgel samples collected at $240 \mathrm{hrs}$. These micrographs provided visual evidence that riverine and marine microgels appeared to be tangled and forming the microscopic gels (Fig. 2a-c), suggesting that aquatic DOC polymers can spontaneously assemble into polymer networks. This is consistent with previous riverine and marine microgel observations [18, 31]. We also examined the microgel concentration and that normalized by DOC concentrations, in order to assess the microgel abundance and the assembly effectiveness ([microgel]/DOC) of the DOC (Fig. 3). The concentration of upstream microgels was $0.99 \pm 0.12 \mathrm{mg} \mathrm{L}^{-1}$ and has the highest DOC concentration of $10.67 \pm 0.73 \mathrm{mg} \mathrm{L}^{-1}$ (Table 1). While mean microgel concentrations of downstream and marine samples observed $1.38 \pm 0.11 \mathrm{mgL}^{-1}$ and $0.62 \pm 0.11 \mathrm{mgL}^{-1}$, the downstream DOC concentration was low at $5.93 \pm 0.86 \mathrm{mgL}^{-1}$. The lowest DOC concentration was found in the marine sample $\left(0.44 \pm 0.01 \mathrm{mgL}^{-1}\right)$. Figure 3 compares the [microgel]/DOC ratio, representing the microgel abundance per each organic carbon unit, of the three different samples. It is noteworthy that the marine [microgel]/DOC ratio was significantly higher than the other two samples $(\mathrm{p}<0.05)$. This illustrates that although the marine sample has the lowest DOC content, it has the higher capability in self-assembling to form microgels. By contrast, the highest DOC was found in the upstream sample, but the highest microgel abundance did not appear on the site. Further investigation of the effects of environmental parameters could help in understanding the possible mechanism behind the phenomenon observed.

\subsection{Possible microgel formation mechanism}

Based on previous research, various possible mechanisms have been suggested for the aquatic DOC aggregation, including that the self-assembly of marine DOC polymers is driven mainly by $\mathrm{Ca}^{2+}$ bonds, which served as cross-linkers in stabilizing aggregates $[13,39,40]$. Therefore, the contribution of $\mathrm{Ca}^{2+}$ binding was the first 
examined [1, 14] and CTC staining was used. CTC staining has been found useful in probing the relative contribution of $\mathrm{Ca}^{2+}$ cross-linking in marine microgels [32, 33]. In this measurement, three samples of aquatic microgels with different origins were stained with CTC to determine the gel fluorescence intensity. Samples collected at the beginning (0th day, original DOC polymer) and at the 10th day (the microgels formed in equilibrium) were stained and measured. The CTC fluorescence intensity was also normalized by DOC concentration to show the fluorescence intensity per each organic carbon unit. The fluorescence intensity/DOC ratio at the 10th day was remarkably higher than at the 0th day $(\mathrm{p}<0.05)$ in all sites (Fig. 4), which is consistent with previously published observations that DOC polymers can form microgels via $\mathrm{Ca}^{2+}$ cross-linking [13, 33]. While the marine gel fluorescence intensity/DOC ratio was also much higher than the other two samples $(\mathrm{p}<0.05)$, the data also followed the trend similar to $\mathrm{Ca}^{2+}$ concentration, salinity and microgel concentration. As the lowest CTC fluorescence intensity and $\mathrm{Ca}^{2+}$ concentration was found in the upstream site, it was speculated that upstream DOC polymers at a lower electrolyte concentration could result in fewer $\mathrm{Ca}^{2+}$ ions available in binding polymer surfaces and less microgel formed. Therefore, extra $\mathrm{NaCl}$ and $\mathrm{CaCl}_{2}$ were added in the native upstream sample to examine the effect of salinity levels and $\mathrm{Ca}^{2+}$ concentrations on the upstream microgel formation. As displayed in Fig. 5a, the addition of extra $\mathrm{NaCl}$ can decrease microgel concentration $(p<0.05)$. This observation may be consistent with our previous suggestion that the presence of extra $\mathrm{NaCl}$ can hinder marine microgel formation, because a large number of $\mathrm{Na}^{+}$ions out-compete $\mathrm{Ca}^{2+}$ for the binding sites on polymers [31]. It was found that increasing $\mathrm{CaCl}_{2}$ concentration did not exhibit differences in the native upstream microgel concentration $(p>0.05)$. Comparing [microgel]/DOC ratio, the ratio clearly showed that upstream samples with extra electrolytes (close to seawater levels) were still significantly smaller than the marine sample $(\mathrm{p}<0.05)$. The relative CTC fluorescence intensity (native upstream sample as 1) may provide one of the possible mechanisms that the addition of extra $\mathrm{NaCl}$ or $\mathrm{CaCl}_{2}$ to the upstream sample cannot effectively facilitate $\mathrm{Ca}$ ions as cross-linking on the polymer surface (CTC intensity much lower than the marine's sample, $\mathrm{p}<0.05$ ) (Fig. 5b). These results suggest that although the upstream sample has the highest DOC concentration, it does not seem to self-aggregate effectively, possibly indicating that non-assembled organic substances are the main portion of this site. However, most of the DOC polymers (like exopolymeric substances (EPS) or other biological secretion) are released by aquatic phytoplankton, microalgae, and bacteria. Their main chemical components containing acidic functional groups (carboxylate, sulfate, and phosphate) can readily chelate ions such as $\mathrm{Ca}$ ions forming microgels, playing a key role in DOC assembly. Therefore, the production of gel particles is not only 
influenced by DOC concentrations [37, 41], but also affected by their physical-chemical characteristics and precursor types [8]. There have been many types of research using isolated EPS as an aquatic DOC polymers model, as self-assembled biopolymers are potentially produced by EPS and other biological secretions [42]. The other study also suggested that anthropogenic substances can inhibit the production of biopolymer, such as bismuth dimercaptopropanol, which could significantly reduce the production of EPS at a level just above the minimum inhibitory concentration [43]. In this case, our upstream and downstream samples were collected from Houjin River, the river passing through four major industrial parks. Lin et al. [28] pointed out that the high concentration of pollutants in water and sediment such as heavy metals, Di-(2-ethylhexyl) phthalate, and phthalate esters, indicate that the potential organic pollutants could have been discharged from these industrial parks. Additionally, rivers also deliver large quantities of terrestrial material such as humic or fulvic substances. Those relatively low molecular weight organic molecules (compared with DOC polymers) are only forming nano scale aggregates or micellar in suitable aqueous environments [44, 45]. Thus, we inferred that the upstream and downstream DOC substances might be mainly composed of non-assembled organic substances (pollutant or low molecular weight organic molecules) and might not be effectively self-assembled into microgels (low [microgel]/DOC ratio), causing the lower microgel concentration. Further evidence of chemical characteristics and possible sources of DOC substances can be illustrated by EEM contour graphs. EEM contour graphs are the result of merging a series of emission scans from excitations over a range of wavelengths and have been used as a tool for the characterization of chromophoric DOC [46, 47]. This technique provides information on the number and type of fluorophores present as well as their abundance. Fig. $6 \mathrm{a}-\mathrm{c}$ demonstrate that the upstream and the downstream DOC samples have distinctive fluorescence properties and wavelengths of the humic-like fluorescence $(\lambda \mathrm{ex} / \mathrm{em}=280-285 / 380-400 \mathrm{~nm} ; \lambda \mathrm{ex} / \mathrm{em}=325-330 / 410-425 \mathrm{~nm})$, and fulvic acid-like centers $(\lambda \mathrm{ex} / \mathrm{em}=250-255 / 445-450 \mathrm{~nm})$ [47]. The range of wavelengths observed here is in agreement with previously published results of wastewater, and polluted water [48]. Thus, the downstream sample has similar fluorescence fingerprints with upstream and the declined fluorescence intensities (compared with upstream). The reason for the decrease of downstream fluorescence intensity may be due to mixing with the sea water. Strait-water containing fulvic acid, marine humic acid is a specific fingerprint of marine samples, and fluorescence peaks were identified at excitation/emission wavelengths of $225-265 / 425-430 \mathrm{~nm}$, 280-285/380-400 $\mathrm{nm}$ and 325-330/410-425 $\mathrm{nm}$, respectively [47].

Our results demonstrated that the assembly effectiveness ([microgel]/DOC) of marine 
samples was much higher than riverine. We infer that the upstream and downstream DOC polymers might be mainly composed of non-assembled organic materials. As results shown above, the contribution of $\mathrm{Ca}^{2+}$ binding on different DOC polymers (CTC fluorescence intensity), addition of extra $\mathrm{Ca}^{2+}$ to DOC polymers, and EEM contour graphs were used to support types and sources affecting microgel abundance in aquatic environments.

\subsection{Sequestering of organic materials and heavy metals}

The microgel formation may provide a tremendous reservoir for DOC. These microgels may interact with surrounding materials that can be removed from the water column by sedimentation. Therefore, in order to investigate the capability of riverine and marine microgels on sequestering organic materials and heavy metals, EEM fluorescence intensities and metals concentration were analyzed at the 0th day and at the 10th day. All samples were filtered through $0.22 \mu \mathrm{m}$ filters to remove microgel from water samples. Comparing the 0th day and the 10th day EEM fluorescence intensity and metals concentration in the dissolved phase can assess the removal of CDOM and heavy metals via polymer aggregation. As illustrated in Fig 7, on the left are sample EEM contour graphs while bar charts on the right show changes in fluorescence intensities. EEM contour graphs showed that the main fluorescence peaks of humic acid-like, humic acid, and fulvic acid-like were typical in upstream and downstream samples; while fulvic acid, marine humic acid and humic acid polymer were characterized in seawater. These graphs provided evidence that the intensity of the main fluorescence peak decreased at the 10th day at all sites, and was effective in removing humic acid and fulvic acid-like from upstream and downstream samples. An average removal rate of $15-40 \%$ was obtained, except humic acid-like (at less than $10 \%$ at both sites). The averaged removal rates of chromophoric organic materials in upstream and downstream samples followed similar trends: fulvic acid-like $\approx$ humic acid $>$ humic acid-like. In the marine sample, three main fluorescence peaks declined significantly, removing approximately $50 \%$ of main chromophoric organic materials. Although removal rates of CDOM in upstream and downstream are less than the marine sample, but upstream and downstream microgels did capture a large quantity of CDOM, due to high CDOM concentration at river sites. The data were expected to show that the EPS biopolymer has many charged groups and polar groups that readily uptake organic materials, such as humic acids, dye, and organic pollutants [49-51]. These findings demonstrate the removal of chromophoric organic materials through the microgel phase resulting in a decrease of fluorescence intensity. Compared with assembled DOC polymers (more than $1000 \mathrm{kDa}$ ), low molecular weight chromophoric organic materials may be adsorbed or bound by microgels and could then be removed from the water column. However, biosorption 
of chromophoric organic materials by microgels showed the same trends in upstream and downstream. The lower extent in biosorption of humic acid-like substances than fulvic acid-like onto microgels can be explained in terms of their molecular size differences. Among these, fulvic acid is comprised of lower molecular weight and less aromatic structure than humic substances [52]. Literature has reported that low molecular weight compounds could be removed more efficiently than high molecular weight materials onto the sorbent surface [53]. In fact, CDOM has a significant effect on biogeochemical activity in aquatic environments and also involves many processes affecting organic matter. Despite photochemical alteration, coagulation, flocculation, CDOM-mineral particle sedimentation, and biological modification are considered to be a loss of riverine CDOM in the oceans $[54,55]$. The pathway and fate for the loss of some fraction of CDOM are still attractive [56, 57]. In this study, our results suggest that fractions of CDOM are able to be sequestered through re-aggregation of different aquatic DOC polymers, which may provide an alternative route for the loss of some fraction of CDOM. One possible mechanism is that DOC polymers are amphiphilic materials, which have hydrophobic and hydrophilic sectors in one polymer molecule [1, 42]; therefore, they readily interact with both polar and non-polar substances. In our inference, the $\mathrm{pH}$ range of our samples was 7.21-8.12, the surface charge of dissoveld organic materials (microgels or CDOM) is negative [58]. The hydrophilic sectors of microgels (self-assembled DOC) may tangle between microgels and CDOM via cation bridge; while the hydrophobic parts may be adsorbed through hydrophobic interaction.

Moreover, with respect to selected heavy metals, the concentration of metals in upstream is generally higher than that downstream, which evidently suggests discharge from upstream to downstream (Fig. 8). Further investigation is much needed to explore the self-removal of heavy metals via polymer aggregation in aquatic systems. Results from our study demonstrate that aquatic polymers are able to scavenge selected heavy metals via polymer aggregation and two-stage removal (metals binding with CDOM and then CDOM sequestered by microgel) (Fig. 8). Comparing the removal rate of metals can reveal the difference in affinity for metal ions - the affinity in order of $\mathrm{Cu} \approx \mathrm{Ni}>\mathrm{Mn}, \mathrm{Cu} \approx \mathrm{Ni}>\mathrm{Mn}$, and $\mathrm{Cu}>\mathrm{Ni}>\mathrm{Mn}$ for upstream, downstream and marine samples, respectively. The surface charge of DOC polymers is negative in the range of $\mathrm{pH} 5-8$; while the $\mathrm{pH}$ values of our samples were found within 7.21-8.12 at river-sea sites. The presence of these anionic functional groups on the surface of polymers offers cation exchange capabilities for complexing heavy metals [59]. The metal affinity order is in agreement with results of other studies. For example, a higher colloidal $\mathrm{Cu}$ than colloidal $\mathrm{Ni}$ was found in the San Francisco Bay estuary, California [60], Narragansett Bay, Rhode Island [61] and in 
the Danshuei River estuary, Taiwan [62]. These affinity characteristic of metals are also similar to Irving-Williams Series $(\mathrm{Cu}(\mathrm{II})>\mathrm{Ni}>\mathrm{Mn})$. The slight differences may be due to different DOC composition, the background concentrations of the metals, competition and other environmental parameters [63]. In fact, the Irving-Williams Series refers to the relative stability of complexes formed by a metal ion, which also explains the wide variety of organic ligands. This may indicate that microgels-metals sequestering capacity is generally affected by ligand interaction [11].

\subsection{Environmental implication}

The aggregation process is an interrelated pathway that determines the fate and sedimentation of particle-surrounding material within aquatic systems. Knowledge of their environmental impact would be highly important and useful. Therefore, assessing the self-assembly of DOC polymers in aquatic ecosystems is of paramount importance to the removal and transport of organic matters and pollutants. Previous studies described the essential role of biopolymers including EPS or colloid in providing association and adsorption sites for organic/inorganic pollutants binding, yet the role of these polymers in mediating the sequestering of surrounding inorganic/organic substances via the "re-aggregation" of DOC in the dissolved phase is largely unexplored. Our data clearly demonstrated that chromophoric organic materials and heavy metals were sequestered through a microgel phase in different water types. Thus, aquatic microgels are highly important in regulating the source strengths of pollutants as they could be removed through the sedimentation of gels. It might be attributed that the number of free or potentially free negatively charged functional groups and hydrophobic sites on the aquatic DOC polymer and CDOM surface is likely responsible for the strong binding, adsorption, and cross-linking of positively charged metal ions [64, 65]. Moreover, similar types of chromophoric materials in upstream and downstream possibly resulted in a similar trend of heavy metals removal, suggesting type and concentration of chromophoric materials may affect the sequestering capacity of metals. The results successfully confirm the idea that microgel phase plays a major role in its capturing, self-cleaning, and affecting the ultimate fate of organic and metal pollutants in aquatic systems.

\section{Conclusion}

In this study, we clearly found that riverine and marine DOC polymers have the capacity for abiotic aggregation in fresh and seawater, which are able to spontaneously form microscopic gels. Sources and physical-chemical characteristics of DOC polymers in the different aquatic environments, probably influence the microgel abundance and behavior. The microgel formation may be directly exported 
as sinking particles, which also have potential applications in CDOM and heavy metal sequestering through microgel phase and removal from the water column. By determining the sequestering of organic materials and heavy metals through DOC polymer aggregation, we have been able to show that microgels play a critical role in determining the sequestering of organic/inorganic substances in aquatic systems. It can be seen that a good understanding of the ecological risk and fate of pollutants should consider the microgel phase besides traditional phase partitioning (truly dissolved, particulate, colloidal). These self-assembled microgels facilitate the accumulation of organic and inorganic materials, and this the accumulation may affect the exposure of higher-trophic-level predators such as filter-feeding fish, invertebrates, and even humans. Additionally, mechanisms of aquatic gel formation may provide potential implications in membrane biofouling and blocking (seawater desalination and wastewater reclamation). Consequently, much detailed information on the interaction between pollutants and microgels (speciation of metal ions, selective adsorption, affinity, and competition) in the aquatic environment will be sought in future studies.

\section{Acknowledgments}

This work was supported by grants from the Ministry of Science and Technology (MOST) and the Ministry of Education of Taiwan, ROC, under Contract Numbers MOST 104-2611-M-110-019 and DOE 01C030703. This work was also partly supported by a grant from the Research Center for Environmental Medicine, Kaohsiung Medical University (KMU-TP105A11 and KMU-TP105A29), Kaohsiung, Taiwan. We gratefully acknowledge critical suggestions from Professor Wei-Chin Chin (School of Engineering, University of California at Merced).

\section{References}

[1] P. Verdugo, Marine Microgels, Ann Rev Mar Sci. 4 (2012) 375-400.

[2] W. He, M. Chen, M.A. Schlautman, J. Hur, Dynamic exchanges between DOM and POM pools in coastal and inland aquatic ecosystems: A review, Sci. Total Environ. 551-552 (2016) 415-428.

[3] R.M. Bundy, K.A. Barbeau, K.N. Buck, Sources of strong copper-binding ligands in Antarctic Peninsula surface waters, Deep-Sea Res. Part II 90 (2013) 134-146.

[4] M.L. Wei-Haas, K.J. Hageman, Y.-P. Chin, Partitioning of polybrominated diphenyl ethers to dissolved organic matter isolated from arctic surface waters, Environ. Sci. Technol. 48 (2014) 4852-4859.

[5] I. Kozyatnyk, S. Bouchet, E. Björn, P. Haglund, Fractionation and 
size-distribution of metal and metalloid contaminants in a polluted groundwater rich in dissolved organic matter, J. Hazard. Mater. 318 (2016) 194-202.

[6] J.P. Croué, M.F. Benedetti, D. Violleau, J.A. Leenheer, Characterization and copper binding of uumic and nonhumic organic matter isolated from the South Platte River: Evidence for the presence of nitrogenous binding site, Environ. Sci. Technol. 37 (2003) 328-336.

[7] B. Muresan, B. Pernet-Coudrier, D. Cossa, G. Varrault, Measurement and modeling of mercury complexation by dissolved organic matter isolates from freshwater and effluents of a major wastewater treatment plant, Appl. Geochem. 26 (2011) 2057-2063.

[8] C. Xu, S. Zhang, C.-y. Chuang, E.J. Miller, K.A. Schwehr, P.H. Santschi, Chemical composition and relative hydrophobicity of microbial exopolymeric substances (EPS) isolated by anion exchange chromatography and their actinide-binding affinities, Mar. Chem. 126 (2011) 27-36.

[9] M. Haitzer, G.R. Aiken, J.N. Ryan, Binding of mercury(II) to dissolved organic matter: The role of the mercury-to-DOM concentration ratio, Environ. Sci. Technol. 36 (2002) 3564-3570.

[10] Z. Wang, C.M. Hessler, Z. Xue, Y. Seo, The role of extracellular polymeric substances on the sorption of natural organic matter, Water Res. 46 (2012) 1052-1060.

[11] N. Koron, J. Faganeli, I. Falnoga, D. Mazej, K. Klun, N. Kovac, Association of macroaggregates and metals in coastal waters, Mar. Chem. 157 (2013) 185-193.

[12] C.-Y. Chuang, P.H. Santschi, L.-S. Wen, L. Guo, C. Xu, S. Zhang, Y. Jiang, Y.-F. Ho, K.A. Schwehr, A. Quigg, C.-C. Hung, M. Ayranov, D. Schumann, Binding of $\mathrm{Th}, \mathrm{Pa}, \mathrm{Pb}, \mathrm{Po}$ and $\mathrm{Be}$ radionuclides to marine colloidal macromolecular organic matter, Mar. Chem. 173 (2015) 320-329.

[13] W.C. Chin, M.V. Orellana, P. Verdugo, Spontaneous assembly of marine dissolved organic matter into polymer gels, Nature 391 (1998) 568-572.

[14] M.V. Orellana, C. Leck, Marine microgels, in: D.A.H.A. Carlson (Eds.) Biogeochemistry of marine dissolved organic matter (Second Edition), Academic Press, Boston, 2015, pp. 451-480.

[15] K.W. Bruland, J.R. Donat, D.A. Hutchins, Interactive influences of bioactive trace metals on biological production in oceanic waters, Limnol. Oceanogr. 36 (1991) 1555-1577.

[16] P. Porcal, A. Amirbahman, J. Kopacek, F. Novak, S.A. Norton, Photochemical release of humic and fulvic acid-bound metals from simulated soil and streamwater, J Environ. Monitor. 11 (2009) 1064-1071.

[17] T. Riedel, H. Biester, T. Dittmar, Molecular fractionation of dissolved organic 
matter with metal salts, Environ. Sci. Technol. 46 (2012) 4419-4426.

[18] M. Kerner, H. Hohenberg, S. Ertl, M. Reckermann, A. Spitzy, Self-organization of dissolved organic matter to micelle-like microparticles in river water, Nature 422 (2003) 150-154.

[19] M.L. Pace, I. Reche, J.J. Cole, A. Fernandez-Barbero, I.P. Mazuecos, Y.T. Prairie, $\mathrm{pH}$ change induces shifts in the size and light absorption of dissolved organic matter, Biogeochemistry 108 (2012) 109-118.

[20] C.-L. Lee, L.-J. Kuo, Quantification of the dissolved organic matter effect on the sorption of hydrophobic organic pollutant: Application of an overall mechanistic sorption model, Chemosphere, 38 (1999) 807-821.

[21] C.-L. Lee, L.-J. Kuo, H.-L. Wang, P.-C. Hsieh, Effects of ionic strength on the binding of phenanthrene and pyrene to humic substances: three-stage variation model, Water Res. 37 (2003) 4250-4258.

[22] Y.-P. Duan, X.-Z. Meng, Z.-H. Wen, R.-H. Ke, L. Chen, Multi-phase partitioning, ecological risk and fate of acidic pharmaceuticals in a wastewater receiving river: The role of colloids, Sci. Total Environ. 447 (2013) 267-273.

[23] Q. Wang, T. Cheng, Y. Wu, Distinct roles of illite colloid and humic acid in mediating arsenate transport in water-saturated sand columns, Water Air Soil Pollut. 226 (2015) 1-15.

[24] M. Dai, Z. Yin, F. Meng, Q. Liu, W.-J. Cai, Spatial distribution of riverine DOC inputs to the ocean: an updated global synthesis, Curr. Opin. Environ. Sustain. 4 (2012) 170-178.

[25] B.-S. Lin, P. Brimblecombe, C.-L. Lee, J.T. Liu, Tracing typhoon effects on particulate transport in a submarine canyon using polycyclic aromatic hydrocarbons, Mar. Chem. 157 (2013) 1-11.

[26] L.-S. Wen, P.H. Santschi, D. Tang, Interactions between radioactively labeled colloids and natural particles: Evidence for colloidal pumping, Geochim. Cosmochim. Acta 61 (1997) 2867-2878.

[27] P. Verdugo, A.L. Alldredge, F. Azam, D.L. Kirchman, U. Passow, P.H. Santschi, The oceanic gel phase: a bridge in the DOM-POM continuum, Mar. Chem. 92 (2004) 67-85.

[28] C. Lin, C.-J. Lee, W.-M. Mao, F. Nadim, Identifying the potential sources of di-(2-ethylhexyl) phthalate contamination in the sediment of the Houjing River in southern Taiwan, J. Hazard. Mater. 161 (2009) 270-275.

[29] J. Ingri, S. Nordling, J. Larsson, J. Rönnegård, N. Nilsson, I. Rodushkin, R. Dahlqvist, P. Andersson, Ö. Gustafsson, Size distribution of colloidal trace metals and organic carbon during a coastal bloom in the Baltic Sea, Mar. Chem. 91 (2004) 117-130. 
[30] P. Verdugo, M.V. Orellana, W.-C. Chin, T.W. Petersen, G. van den Eng, R. Benner, J.I. Hedges, Marine biopolymer self-assembly: Implications for carbon cycling in the ocean, Faraday Discuss. 139 (2008) 393-398.

[31] R.-F. Shiu, W.-C. Chin, C.-L. Lee, Carbonaceous particles reduce marine microgel formation, Sci. Rep. 4 (2014) 5856.

[32] C.S. Chen, J.M. Anaya, S.J. Zhang, J. Spurgin, C.Y. Chuang, C. Xu, A.J. Miao, E.Y.T. Chen, K.A. Schwehr, Y.L. Jiang, A. Quigg, P.H. Santschi, W.C. Chin, Effects of engineered nanoparticles on the assembly of exopolymeric substances from phytoplankton, PLoS One 6 (2011) e21865.

[33] C.-S. Chen, J.M. Anaya, E.Y.T. Chen, E. Farr, W.-C. Chin, Ocean warming-acidification synergism undermines dissolved organic matter assembly, PLoS One 10 (2015) e0118300.

[34] K.-C. Chang, C.-L. Lee, P.-C. Hsieh, P. Brimblecombe, S.-M. Kao, pH and ionic strength effects on the binding constant between a nitrogen-containing polycyclic aromatic compound and humic acid, Environ. Sci. Pollut. Res. 22 (2015) 13234-13242.

[35] E.P. Achterberg, C.B. Braungardt, R.C. Sandford, P.J. Worsfold, UV digestion of seawater samples prior to the determination of copper using flow injection with chemiluminescence detection, Anal. Chim. Acta 440 (2001) 27-36.

[36] P.G. De Gennes, L. Leger, Dynamics of entangled polymer chains, Annu. Rev. Phys. Chem. 33 (1982) 49-61.

[37] M.V. Orellana, P. Verdugo, Ultraviolet radiation blocks the organic carbon exchange between the dissolved phase and the gel phase in the ocean, Limnol. Oceanogr. 48 (2003) 1618-1623.

[38] P. Verdugo, P.H. Santschi, Polymer dynamics of DOC networks and gel formation in seawater, Deep-Sea Res. Part II 57 (2010) 1486-1493.

[39] A.W. Decho, Microbial biofilms in intertidal systems: An overview, Cont. Shelf Res. 20 (2000) 1257-1273.

[40] J.S. Chow, C. Lee, A. Engel, The influence of extracellular polysaccharides, growth rate, and free coccoliths on the coagulation efficiency of Emiliania huxleyi, Mar. Chem. 175 (2015) 5-17.

[41] P. Verdugo, The role of marine gel-phase on carbon cycling in the ocean, Mar. Chem. 92 (2004) 65-66.

[42] Y.-X. Ding, W.-C. Chin, A. Rodriguez, C.-C. Hung, P.H. Santschi, P. Verdugo, Amphiphilic exopolymers from Sagittula stellata induce DOM self-assembly and formation of marine microgels, Mar. Chem. 112 (2008) 11-19.

[43] A.R. Badireddy, S. Chellam, S. Yanina, P. Gassman, K.M. Rosso, Bismuth dimercaptopropanol (BisBAL) inhibits the expression of extracellular 
polysaccharides and proteins by Brevundimonas diminuta: Implications for membrane microfiltration, Biotechnol. Bioeng. 99 (2008) 634-643.

[44] R. Sutton, G. Sposito, Molecular structure in soil humic substances: The new view, Environ. Sci. Technol. 39 (2005) 9009-9015.

[45] C. Colombo, G. Palumbo, R. Angelico, H.G. Cho, O. Francioso, A. Ertani, S. Nardi, Spontaneous aggregation of humic acid observed with AFM at different pH, Chemosphere 138 (2015) 821-828.

[46] P.G. Coble, Characterization of marine and terrestrial DOM in seawater using excitation-emission matrix spectroscopy, Mar. Chem. 51 (1996) 325-346.

[47] W. Chen, P. Westerhoff, J.A. Leenheer, K. Booksh, Fluorescence excitation-emission matrix regional integration to quantify spectra for dissolved organic matter, Environ. Sci. Technol. 37 (2003) 5701-5710.

[48] N. Hudson, A. Baker, D. Reynolds, Fluorescence analysis of dissolved organic matter in natural, waste and polluted waters - a review, River Res. Appl. 23 (2007) 631-649.

[49] A. Liu, I.-S. Ahn, C. Mansfield, L.W. Lion, M.L. Shuler, W.C. Ghiorse, Phenanthrene desorption from soil in the presence of bacterial extracellular polymer: observations and model predictions of dynamic beheavior, Water Res. 35 (2001) 835-843.

[50] M. Esparza-Soto, P. Westerhoff, Biosorption of humic and fulvic acids to live activated sludge biomass, Water Res. 37 (2003) 2301-2310.

[51] G.-P. Sheng, M.-L. Zhang, H.-Q. Yu, Characterization of adsorption properties of extracellular polymeric substances (EPS) extracted from sludge, Colloid Surf. B-Biointerfaces 62 (2008) 83-90.

[52] E.M. Thurman, Aquatic humic substances, Organic Geochemistry of Natural Waters, Springer, Netherlands, 1985, pp. 273-361.

[53] G. Carlson, J. Silverstein, Effect of molecular size and charge on biofilm sorption of organic matter, Water Res. 32 (1998) 1580-1592.

[54] A. Stubbins, V. Hubbard, G. Uher, C.S. Law, R.C. Upstill-Goddard, G.R. Aiken, K. Mopper, Relating carbon monoxide photoproduction to dissolved organic matter functionality, Environ. Sci. Technol. 42 (2008) 3271-3276.

[55] Z.-P. Mei, F.J. Saucier, V. Le Fouest, B. Zakardjian, S. Sennville, H. Xie, M. Starr, Modeling the timing of spring phytoplankton bloom and biological production of the Gulf of St. Lawrence (Canada): Effects of colored dissolved organic matter and temperature, Cont. Shelf Res. 30 (2010) 2027-2042.

[56] S.E. DeVilbiss, Z. Zhou, J.V. Klump, L. Guo, Spatiotemporal variations in the abundance and composition of bulk and chromophoric dissolved organic matter in seasonally hypoxia-influenced Green Bay, Lake Michigan, USA, Sci. Total 
Environ. 565 (2016) 742-757.

[57] Y. Zhou, Y. Zhang, E. Jeppesen, K.R. Murphy, K. Shi, M. Liu, X. Liu, G. Zhu, Inflow rate-driven changes in the composition and dynamics of chromophoric dissolved organic matter in a large drinking water lake, Water Res. 100 (2016) 211-221.

[58] K. Kristian, P. H. Nielsen, Desorption of organic macromolecules from activated sludge: effect of ionic composition, Water Res.31 (1997) 1665-1672.

[59] P.M. Joshi, A.A. Juwarkar, In vivo studies to elucidate the role of extracellular polymeric substances from azotobacter in immobilization of heavy metals, Environ. Sci. Technol. 43 (2009) 5884-5889.

[60] S.A. Sanudo-Wilhelmy, I. Rivera-Duarte, A. Russell Flegal, Distribution of colloidal trace metals in the San Francisco Bay estuary, Geochim. Cosmochim. Acta 60 (1996) 4933-4944.

[61] M.L. Wells, G.J. Smith, K.W. Bruland, The distribution of colloidal and particulate bioactive metals in Narragansett Bay, RI, Mar. Chem. 71 (2000) 143-163.

[62] K.-T. Jiann, L.-S. Wen, P.H. Santschi, Trace metal (Cd, Cu, Ni and $\mathrm{Pb}$ ) partitioning, affinities and removal in the Danshuei River estuary, a macro-tidal, temporally anoxic estuary in Taiwan, Mar. Chem. 96 (2005) 293-313.

[63] H. Irving, R.J.P. Williams, The stability of transition-metal complexes, Journal of the Chemical Society (Resumed) (1953) 3192-3210.

[64] G.-P. Sheng, J. Xu, H.-W. Luo, W.-W. Li, W.-H. Li, H.-Q. Yu, Z. Xie, S.-Q. Wei, F.-C. Hu, Thermodynamic analysis on the binding of heavy metals onto extracellular polymeric substances (EPS) of activated sludge, Water Res. 47 (2013) 607-614.

[65] W.-W. Tang, G.-M. Zeng, J.-L. Gong, J. Liang, P. Xu, C. Zhang, B.-B. Huang, Impact of humic/fulvic acid on the removal of heavy metals from aqueous solutions using nanomaterials: A review, Sci. Total Environ. 468-469 (2014) 1014-1027. 


\section{Figure captions}

Figure 1. The self-assembly of DOC polymer as a function of time. DOC samples were collected from upstream and downstream of the Houjin River and Taiwan Strait. Each point is the average \pm SD in more than five samples $(n \geqq 5)$.

Figure 2. SEM images of microgel at different aquatic systems: (a) upstream, (b) downstream, (c) Taiwan Strait (scale bar $=4 \mu \mathrm{m})$.

Figure 3. The concentration of microgels and [microgel]/DOC ratio. Microgel samples were collected at the 10th day $(n=3)$.

Figure 4. Fluorescence intensity measurements of CTC for fresh and marine microgels ( $\mathrm{n} \geqq 3)$.

Figure 5. Effects of extra $\mathrm{NaCl}$ and $\mathrm{CaCl}_{2}$ on the microgel concentration (a) and $\mathrm{CTC}$ fluorescence intensity (b) of upstream water samples $(n=3)$.

Figure 6. EEM contour graphs of (a) upstream (b) downstream and (c) Taiwan Strait DOC samples ( $\mathrm{X}$ axis: excitation wavelength; $\mathrm{Y}$ axis: emission wavelength).

Figure 7. Characterization of the different DOC in the (a) upstream (b) downstream and (c) Taiwan Strait. Bar charts show the mean of each component fluorescence maximum and their removal rate via polymer aggregation $(n=3)$.

Figure 8. Sequestering of heavy metals via polymer aggregation (a) upstream (b) downstream and (c) Taiwan Strait $(n=3)$. 


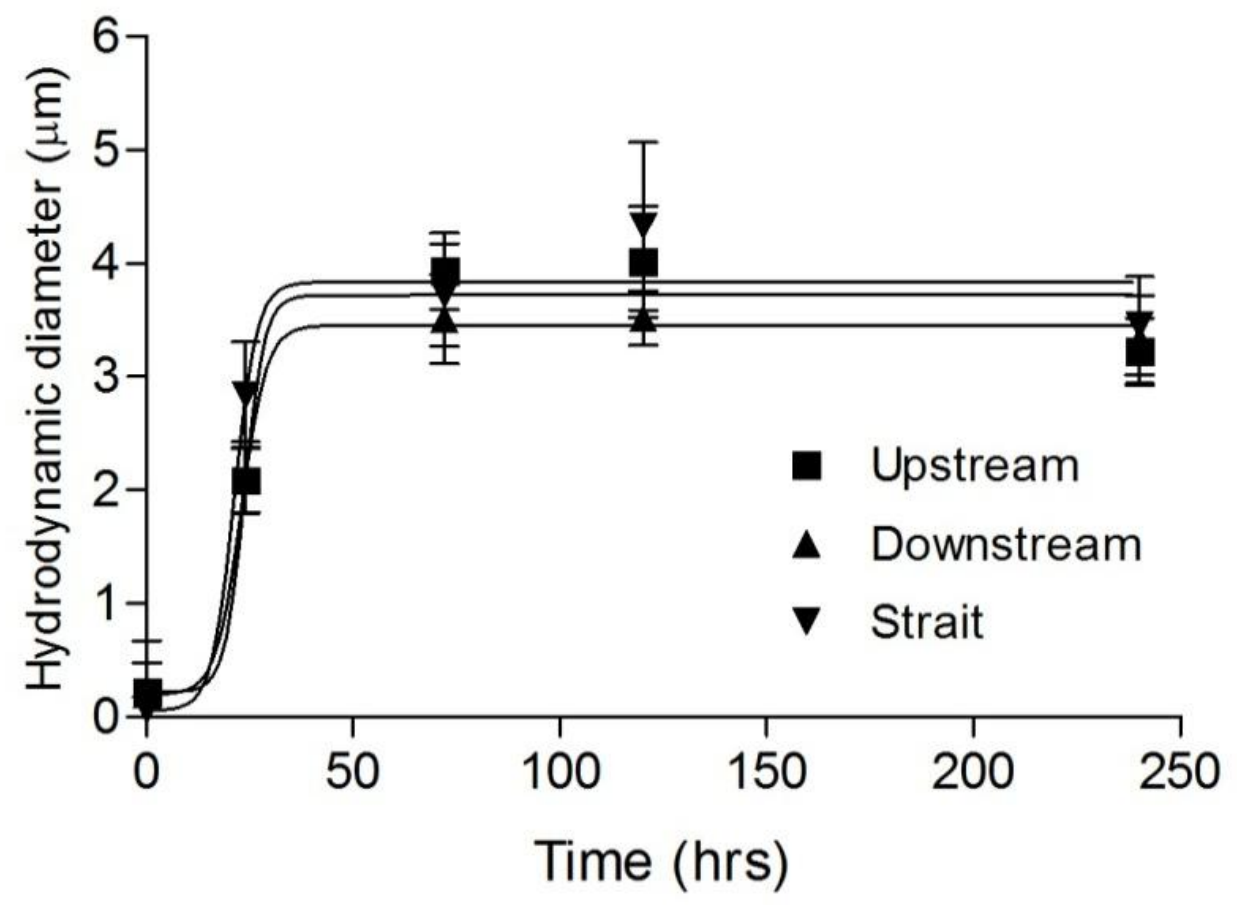

Figure 1 


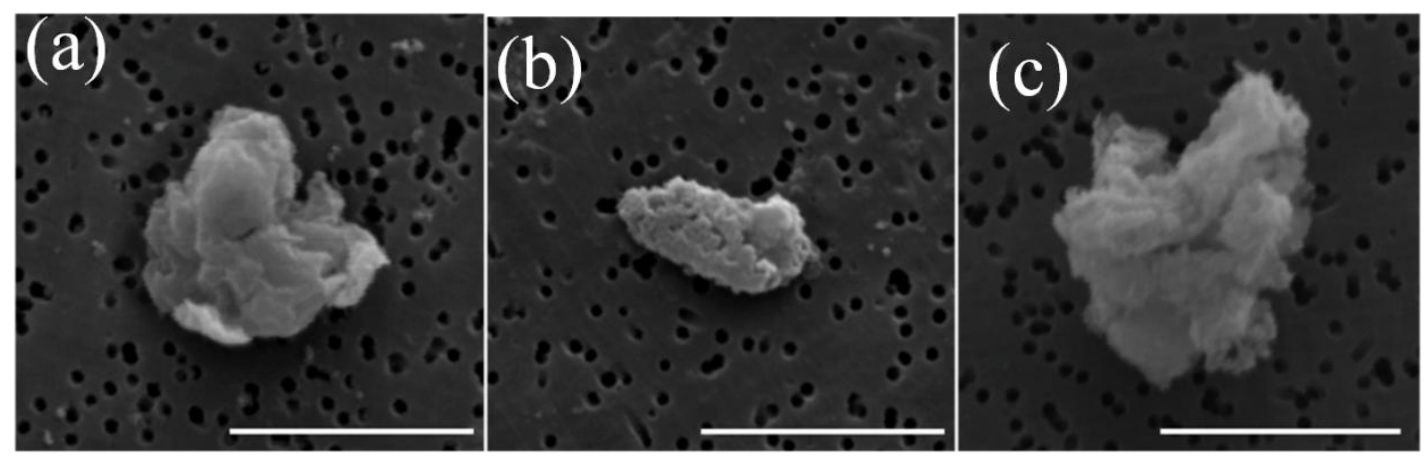

Figure 2 


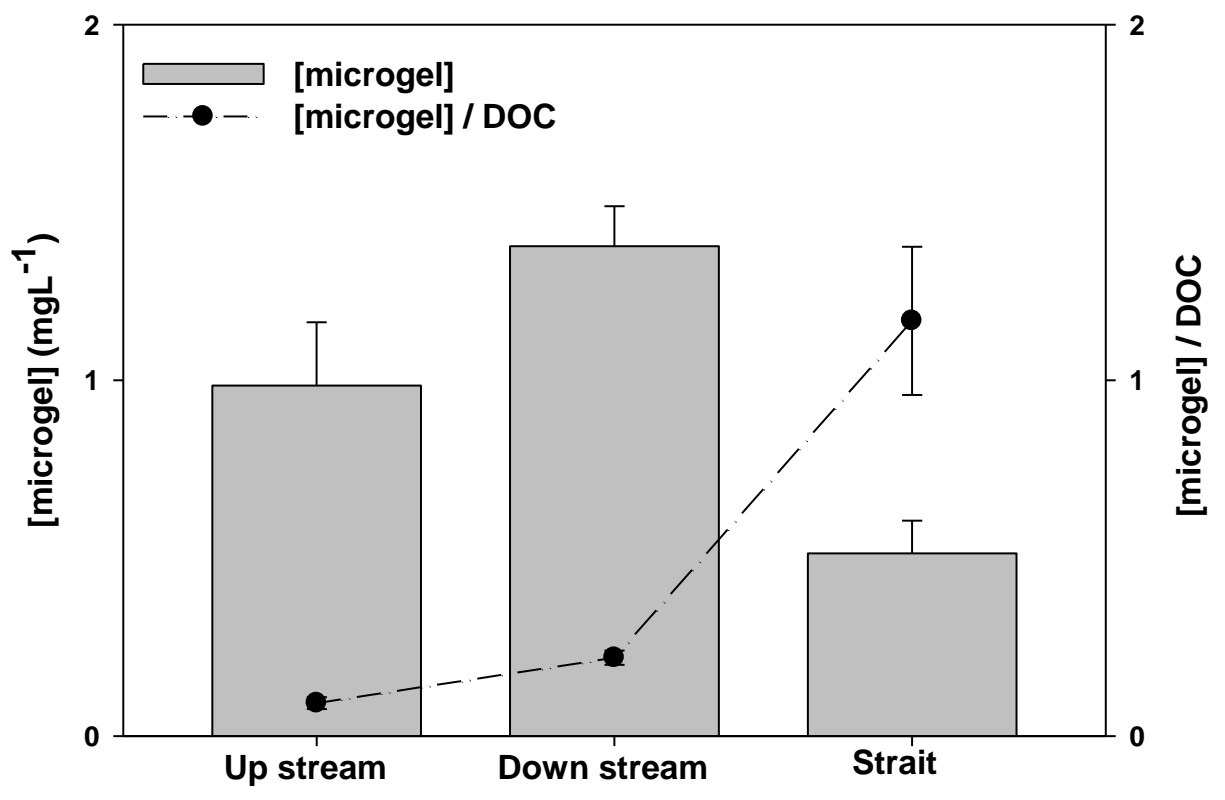

Figure 3 


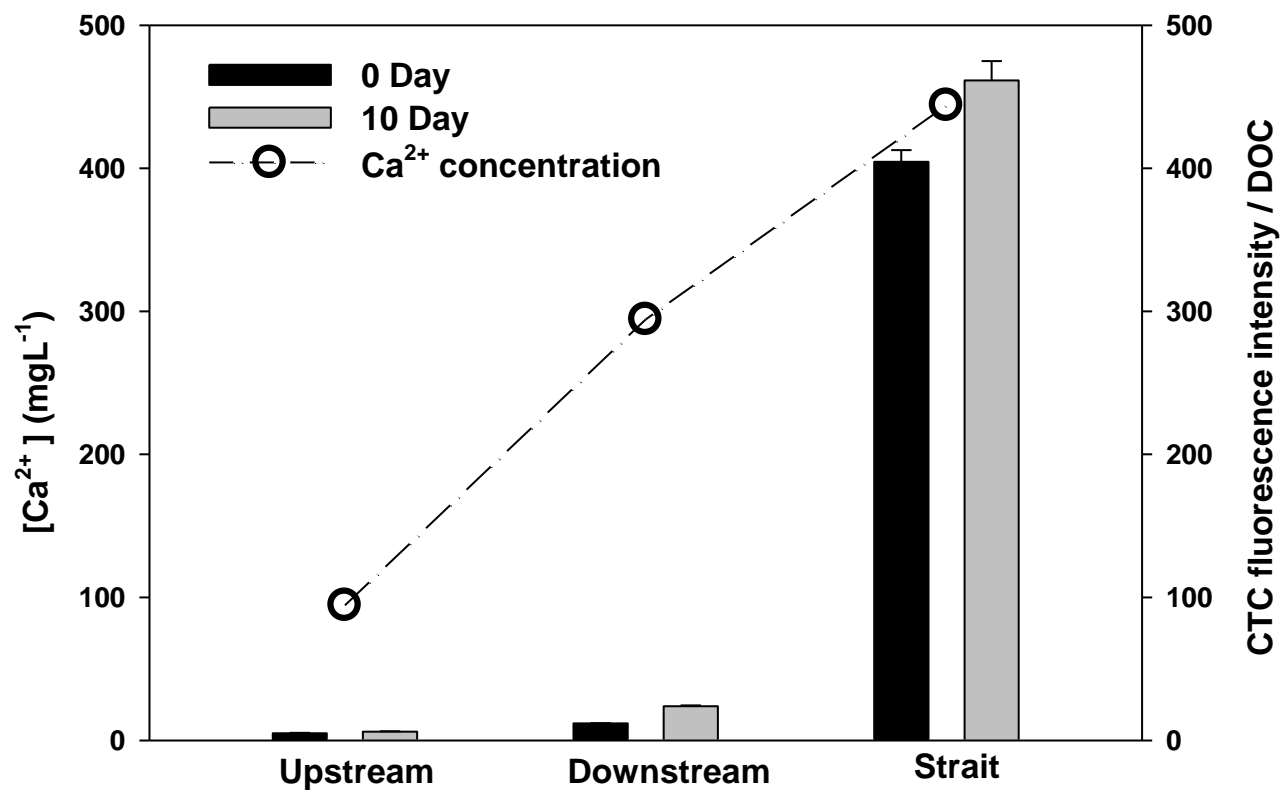

Figure 4 

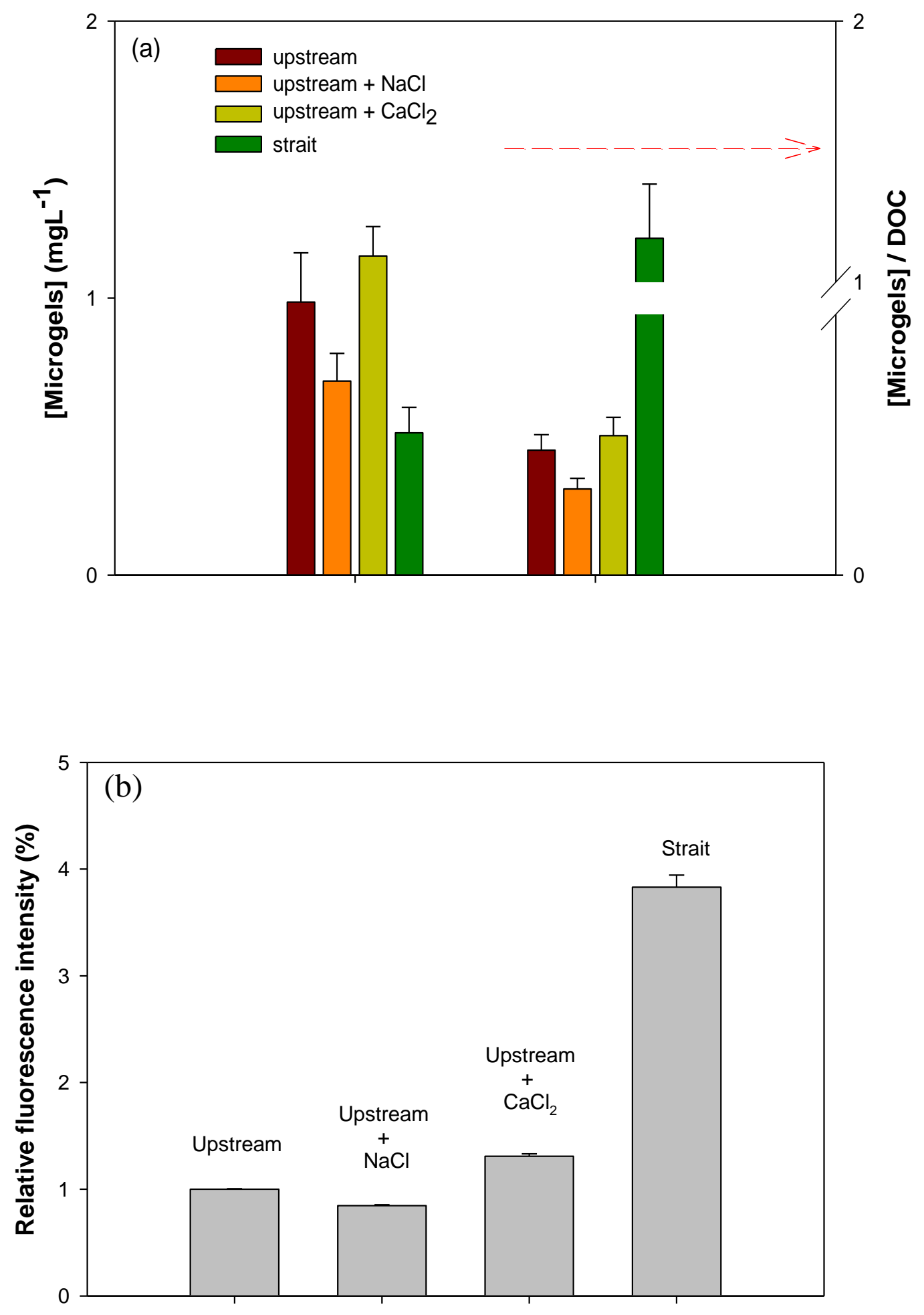

Figure 5 

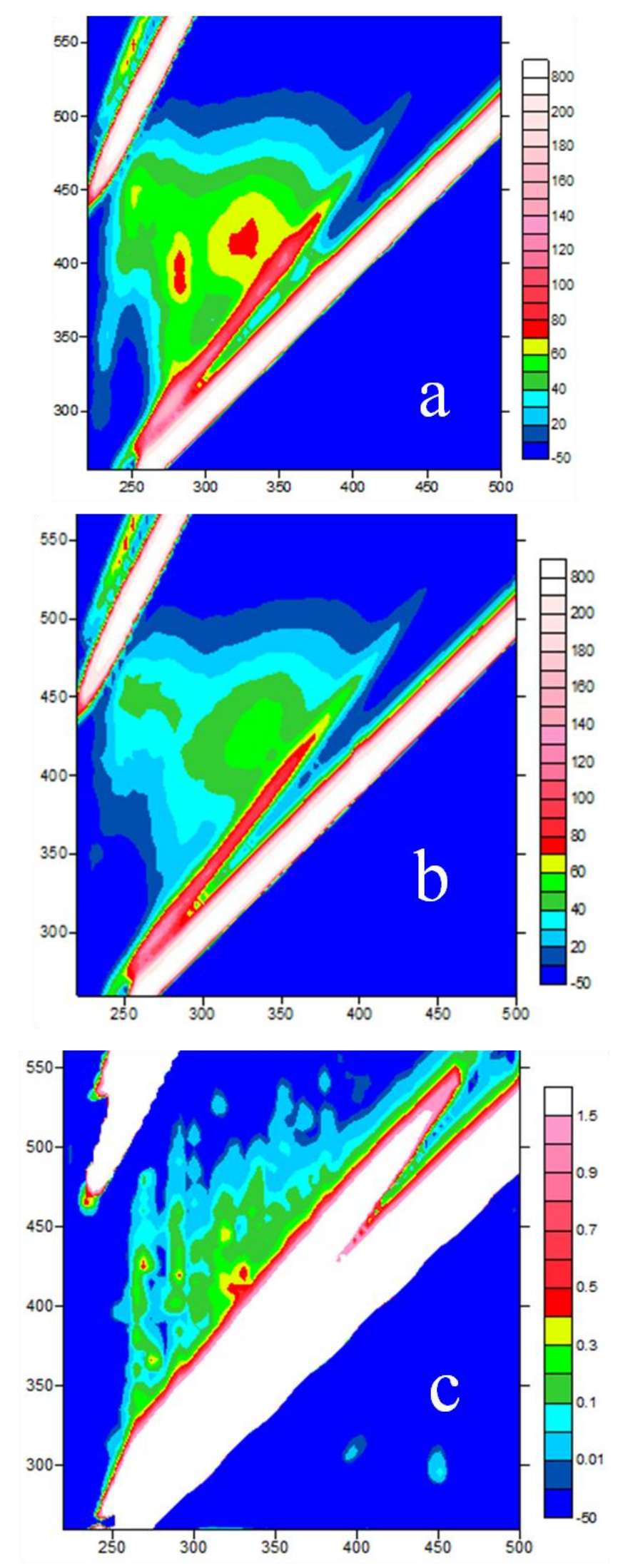

Figure 6 
(a)

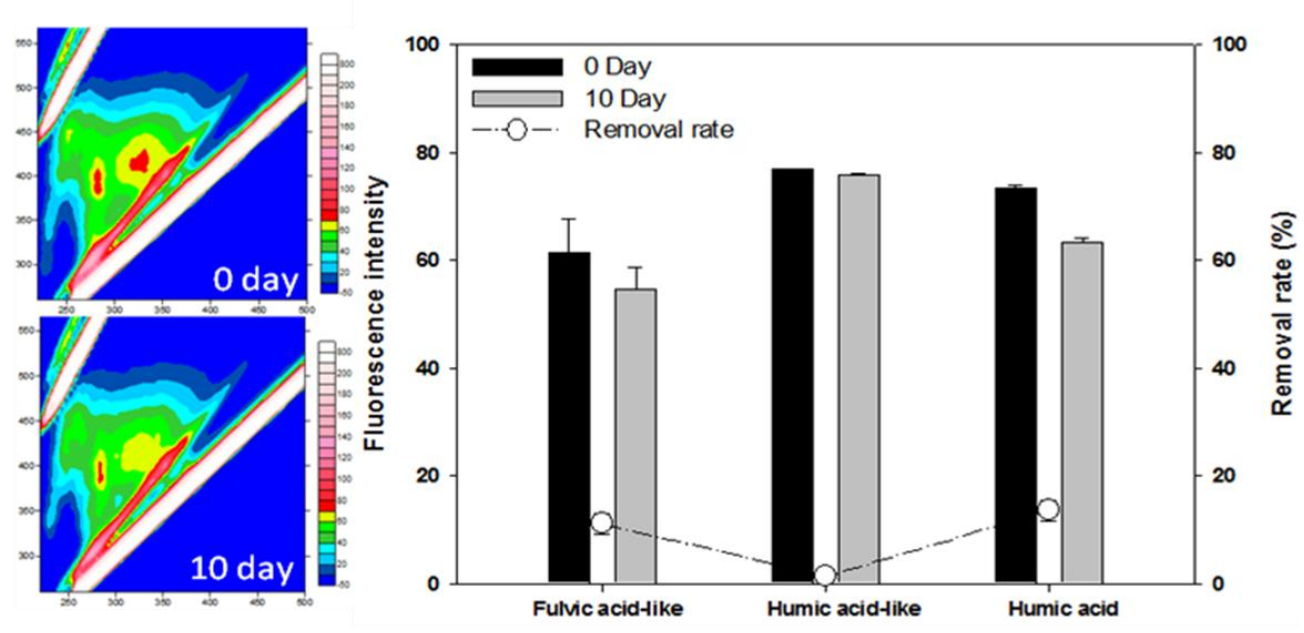

(b)

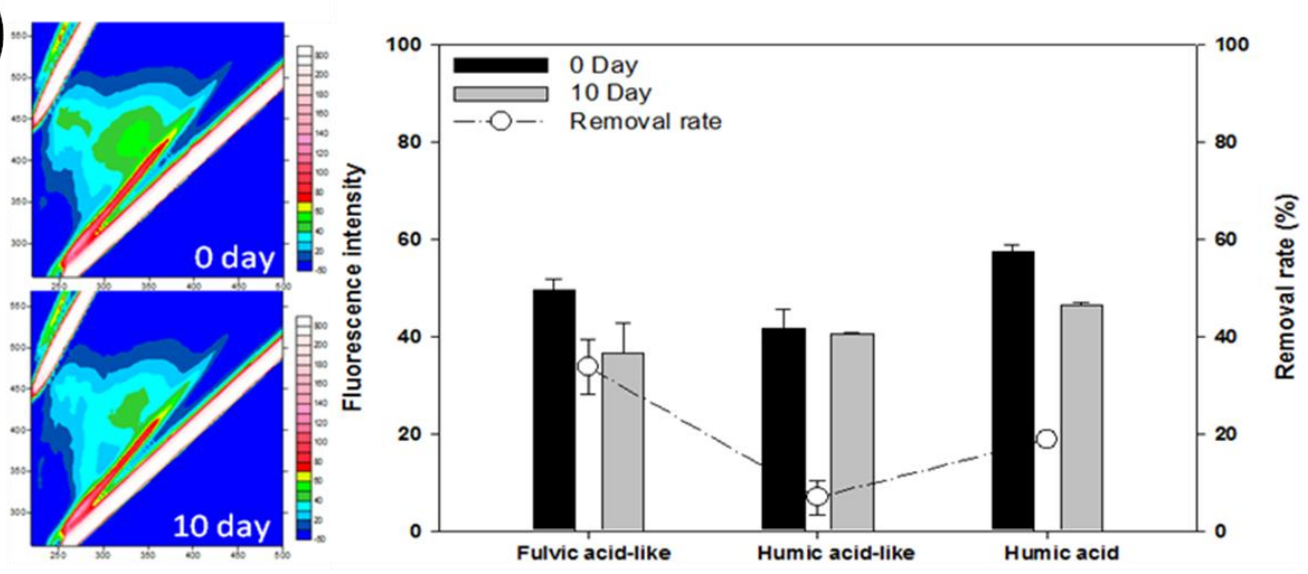

(c)

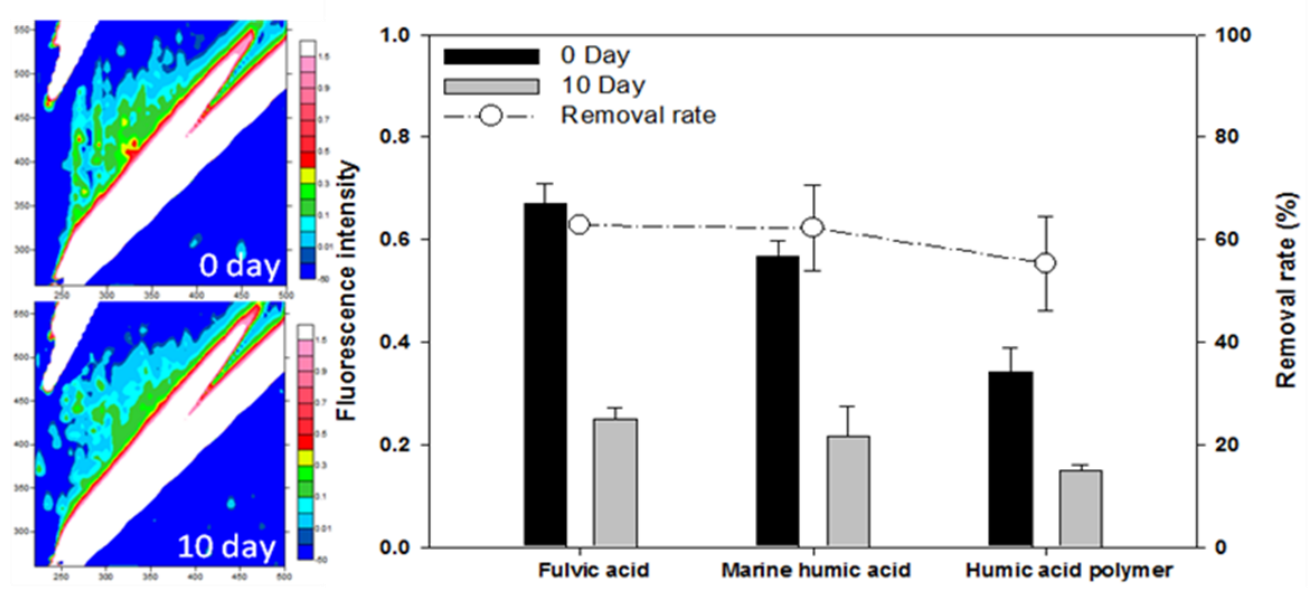

Figure 7 

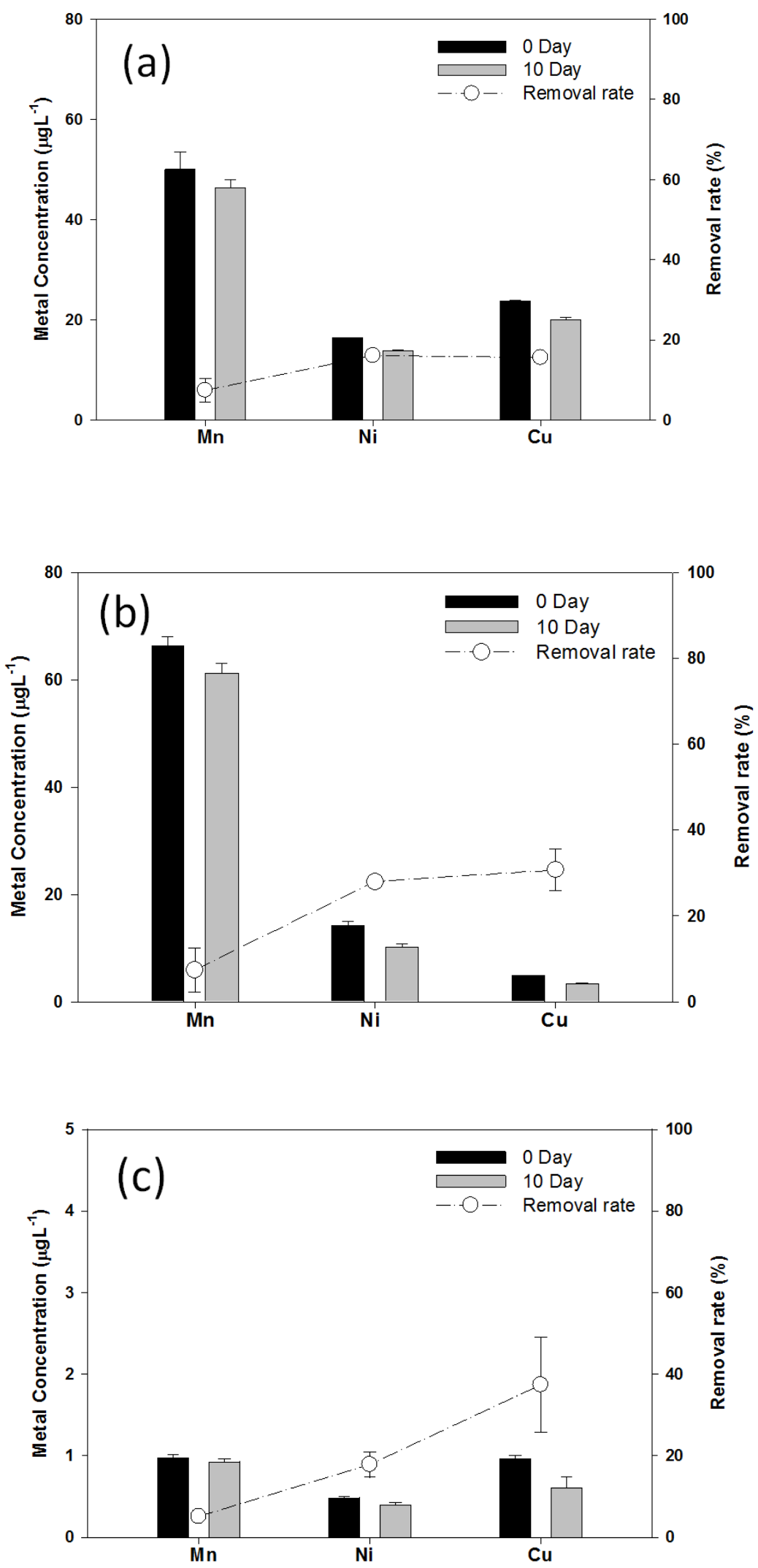

Figure 8 